\title{
Digital Simulation of Thirty Bus System with Interline Power Flow Controller
}

\author{
G. Irusapparajan and S. Rama Reddy
}

\begin{abstract}
IPFCs provide independent control of reactive power of each individual line, while active power could be transferred via the DC-link between the compensated lines. An IPFC can also be used to equalize active/ reactive power between transmission lines, and transfer power from overloaded lines to under-loaded lines .Thirty bus system is modeled and the simulation results are presented.
\end{abstract}

Index Terms-FACTS, IPFC, simulink, SSSC, TCSC.

\section{INTRODUCTION}

The IPFC addresses the problem of compensating a number of transmission lines at a given substation. Standing alone series capacitive compensators normally are used to increase the transmittable active power over a given line however they are unable to control the reactive power flow in, and thus the proper load balancing of the line. Therefore in an IPFC, series VSCs are tied together at their DC link capacitors. Because of the common DC circuit there is possible to exchange the real power between transmission lines and therefore series VSCs can provide also reactive power flow. In an IPFC, the exchanged real power can flow bi-directionally between AC lines which may be of different frequencies, thus making the IPFC an asynchronous tie.

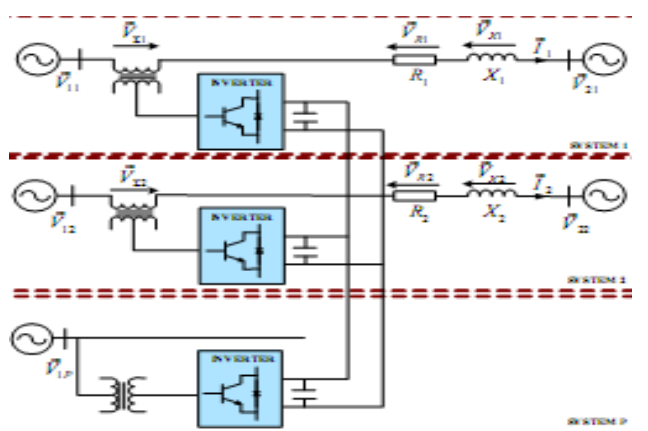

Fig. 1. Single line diagram of an Interline Power Flow Controller with two series VSCs and one parallel VSC

The general form of an IPFC is shown in Fig. 1. It employs a number of series DC-to-AC converters, namely SSSC, each providing series compensation for a different System and one parallel DC-to-AC converter, namely STATCOM, coupled to the IPFC's common DC link, to provide shunt reactive compensation and supply or absorb the overall active power

Manuscript received March 16, 2011; revised July 26, 2011.

G. Irusapparajan, Research Scholar, is with the Bharath University Chennai, India.(e-mail: irusrajan@gmail.com).

S. RamaReddy, Professor was with Anna University, Chennai, India. $\mathrm{He}$ is now with the Department of Electrical and Electronics Engineering, Jerusalem Engineering College, Chennai, India. (email: srr_victory@yahoo.com ). deficit of the combined SSSC's. In Fig. 1 System 1 is represented by resistance $R_{1}$ and reactance $X_{1}$, and have a sending-end bus voltage $V_{11}$ and a receiving-end bus voltage $V_{21}$. Similarly, System 2 is represented by $R_{1}$ and $X_{1}$, with voltages $\mathrm{V}_{12}$ and $\mathrm{V}_{22}$. As it was told earlier the series converters, which control power flow by injecting fully controllable voltages $\mathrm{V}_{\Sigma 1}$ and $\mathrm{V}_{\Sigma_{2} \text {, do not only provide series }}$ reactive compensation but can also be controlled to supply active power to the common DC link from its own transmission line. This scheme requires then a rigorous Maintenance of the overall power balance at the common DC terminal by appropriate control action. For N Systems with parallel inverter one can write the following rule:

$$
\mathrm{P}_{\Sigma_{1}}+\mathrm{P}_{\Sigma^{2}}+\mathrm{P}_{\Sigma^{3}}+\ldots \ldots \ldots \ldots . .+\mathrm{P}_{\Sigma \mathrm{N}}+\mathrm{Pp}=0
$$

where $\mathrm{P}_{\sum \mathrm{n}}$-active power supplied/absorbed by the series VSC in System $n(n \in 1,2 \ldots \mathrm{N}) ; \mathrm{Pp}$ - active power supplied/ absorbed by the parallel VSC.

In the basic configuration of an IPFC as shown in Fig. 1, the active and reactive powers are given by the following equations,

$$
\left.\begin{array}{c}
P_{2 n}^{\prime}=\frac{V_{1 n} \cdot V_{2 n}}{X_{n}} \sin \left(\delta_{n}\right)+\frac{V_{\Sigma n} \cdot V_{2 n}}{X_{n}} \sin \left(\delta_{n}+\sigma_{n}\right) \\
Q_{2 n}^{\prime}=\frac{V_{2 n}^{2}}{X_{n}}-\frac{V_{1 n} \cdot V_{2 n}}{X_{n}} \cos \left(\delta_{n}\right)-\frac{V_{\Sigma n} \cdot V_{2 n}}{X_{n}} \cos \left(\delta_{n}+\sigma_{n}\right) \\
P_{\Sigma n}^{\prime}=\frac{V_{\Sigma n} \cdot V_{2 n}}{X_{n}} \sin \left(\delta_{n}+\sigma_{n}\right)-\frac{V_{1 n} \cdot V_{\Sigma n}}{X_{n}} \sin \left(\sigma_{n}\right) \\
Q_{\Sigma n}^{\prime}=\frac{V_{\Sigma n}^{2}}{X_{n}}+\frac{V_{1 n} \cdot V_{\Sigma n}}{X_{n}} \cos \left(\sigma_{n}\right)-\frac{V_{\Sigma n} \cdot V_{2 n}}{X_{n}} \cos \left(\delta_{n}+\sigma_{n}\right)
\end{array}\right\}
$$

where $\mathrm{P}^{\prime}{ }_{\mathrm{n}}, \mathrm{Q}^{\prime} 2 \mathrm{n}$ - respectively active and reactive powers flowing into receiving-end bus in System n, for $R n=0 ; P^{\prime} \Sigma n$, $Q^{\prime}{ }_{\Sigma n}$ - the active and reactive powers injected into System n by the series VSC, for $\mathrm{Rn}=0$.

Considering situation when $R n \neq 0$, equation (2) can be rewritten:

$$
\left.\begin{array}{c}
P_{2 n}=b_{n} \cdot\left(-Q_{2 n}^{\prime}\right)+a_{n} \cdot P_{2 n}^{\prime} \\
Q_{2 n}=b_{n} \cdot P_{2 n}^{\prime}+a_{n} \cdot Q_{2 n}^{\prime} \\
P_{\Sigma n}=b_{n} \cdot Q_{\Sigma n}^{\prime}+a_{n} \cdot P_{\Sigma n}^{\prime} \\
Q_{\Sigma n}=b_{n} \cdot\left(-P_{\Sigma n}^{\prime}\right)+a_{n} \cdot Q_{\Sigma n}^{\prime}
\end{array}\right\}
$$

where

$$
\begin{aligned}
& a_{n}=X_{n}{ }^{2} / R_{n}^{2}+X_{n}^{2} \\
& b_{n}=R_{n} X_{n} / R_{n}^{2}+X_{n}^{2}
\end{aligned}
$$

Taking into account an IPFC as shown in Fig. 2, series VSC in every System can control freely power flow $\mathrm{P}_{2 n}, \mathrm{Q}_{2 \mathrm{n}}$ at the receiving-end bus. The only limitations there are series and parallel VSC's ratings. However in situation when parallel VSC cannot secure (1) because of limitations related to its ratings, one or group of the series VSCs can be designated as the primary where each of them has two degrees of control freedom: the active power and the reactive 


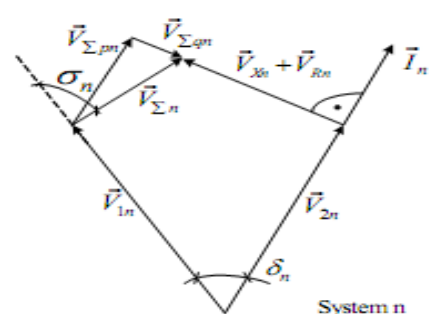

Fig.2. Vector diagram for IPFC with consideration of line resistance

power at the receiving-end bus by adjusting the injected voltage $\mathrm{V}_{\Sigma \mathrm{n}}$. The remaining one or group of the series VSCs, which has only one degree of control freedom, can be used to compensate the active power demand from the primary VSCs to maintain the DC link voltage. As the operating points of the primary VSCs are random, i.e. some of them absorb active power from the DC link while remaining VSCs deliver at the same time, the power rating of the secondary VSCs may not necessary be large, thus keeping the rating of the IPFC at a reasonable value which also makes its practical application feasible. The above literature does not deal with IPFC in thirty bus system. This work proposes IPFC for thirty bus system.

\section{Simulation Results}

The simulation is done using matlab and the results are presented. Model of 30 bus system is shown in Fig. 3a.Lines are represented by their series impedences. Load is represented by series combination of $\mathrm{R}$ and L.Voltage, Real and reactive powers at bus 11 are shown in Fig.s 3b, 3c and $3 \mathrm{~d}$ respectively.

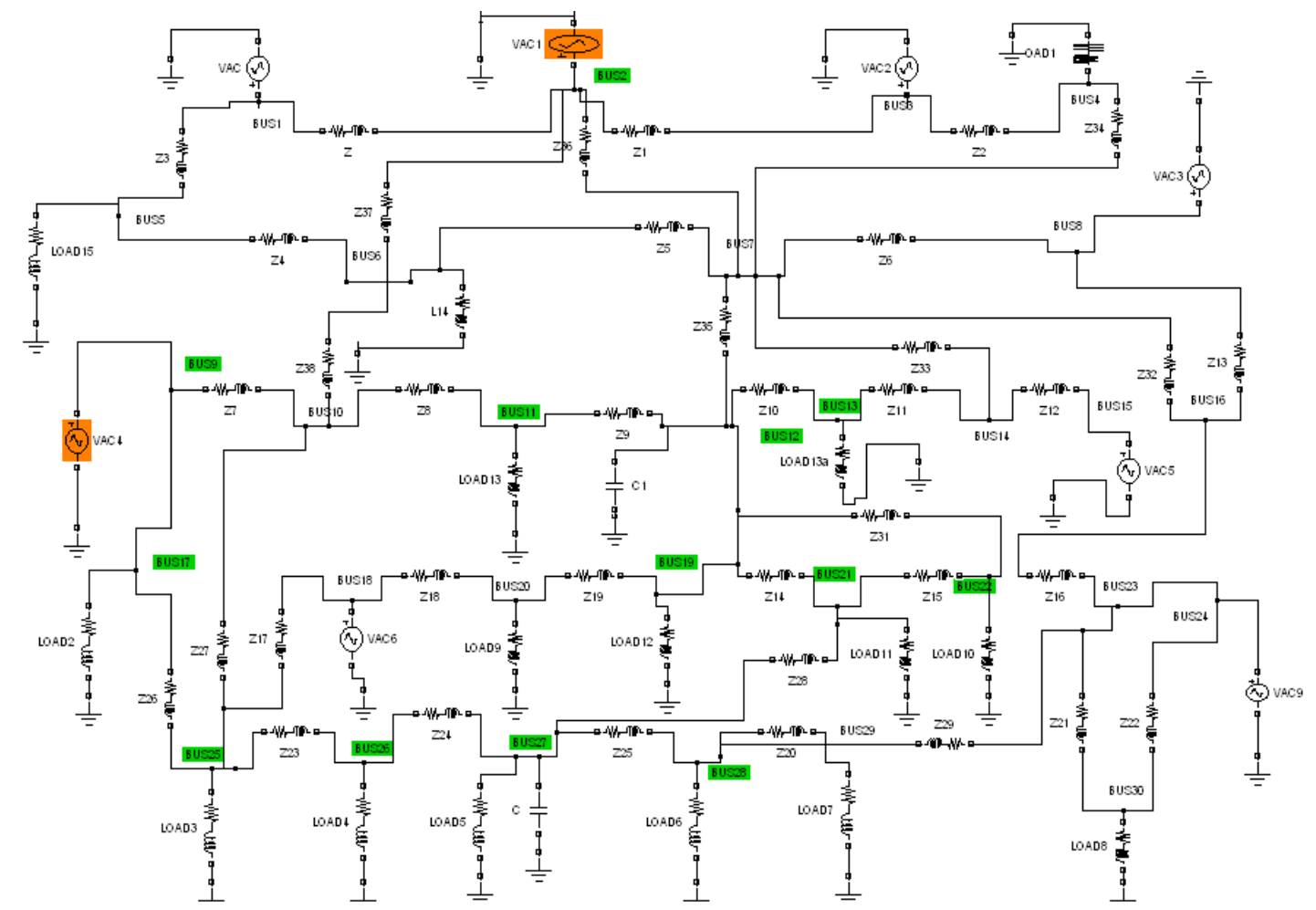

Fig.3a. IEEE 30 bus system

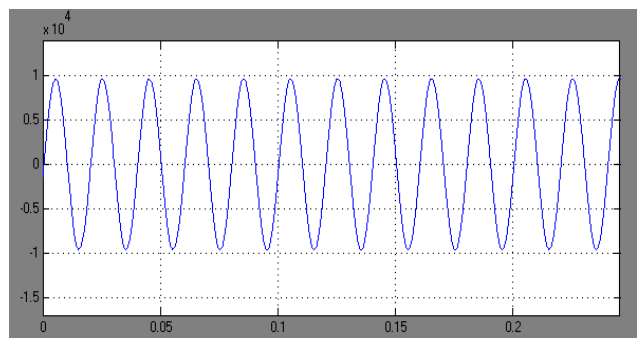

Fig.3b. Voltage across 11 bus

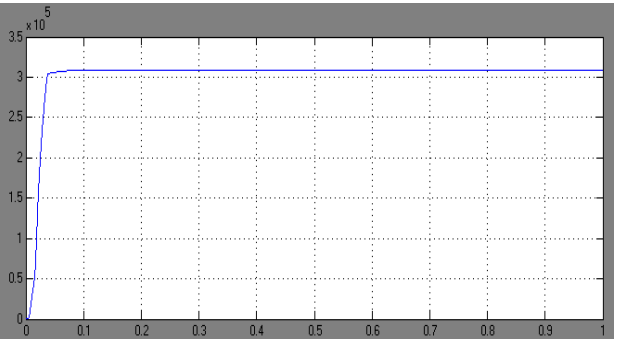

Fig.3c. Real power at 11 bus

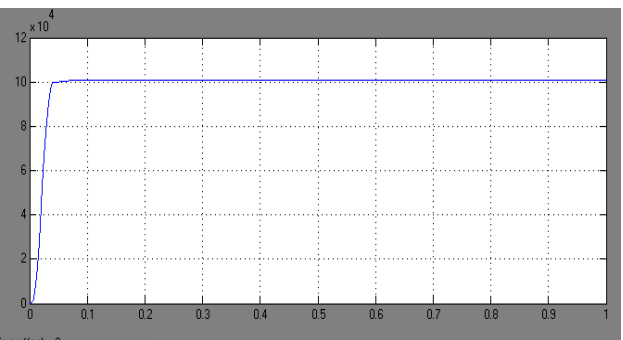

Fig.3d. Reactive power at 11 bus

30 bus systems with IPFC are shown in Fig. 4a. The voltage, real power and reactive power with IPFC at bus 11 are shown in Fig.s 4b, 4c and 4d respectively.

The real power, reactive power and voltage of different buses with and without IPFC are given in table-1. It can be seen that the real and reactive powers increases due to the presence of IPFC.

Injected voltage and reactive power of different buses are given in Table 2.The reactive power increases with the increase in the injected voltage. 


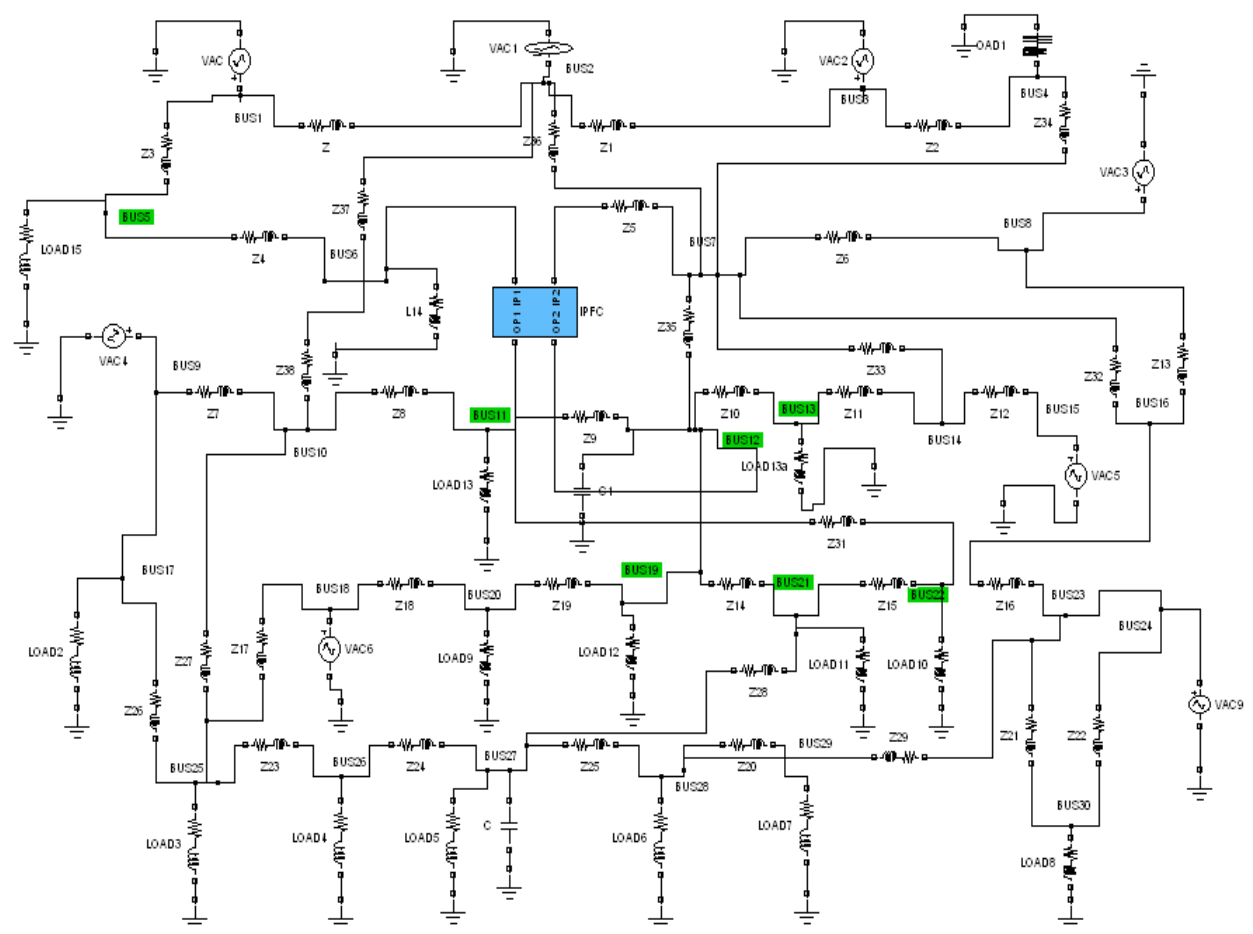

Fig.4a. 30 Bus system with IPFC

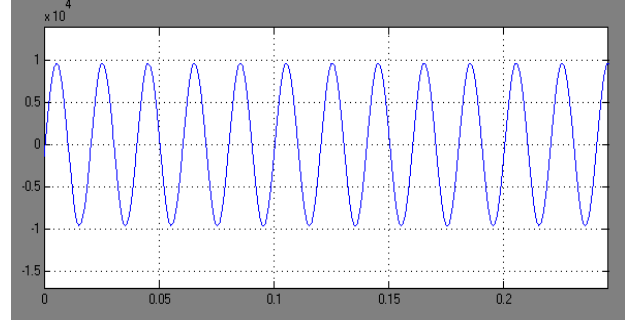

Fig.4b. Voltage at 11 bus

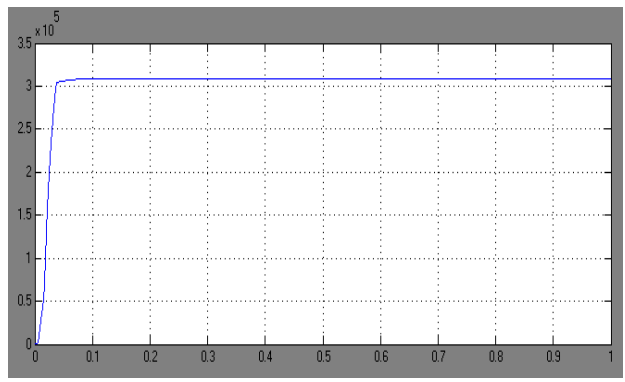

Fig.4c. Real power at 11 bus

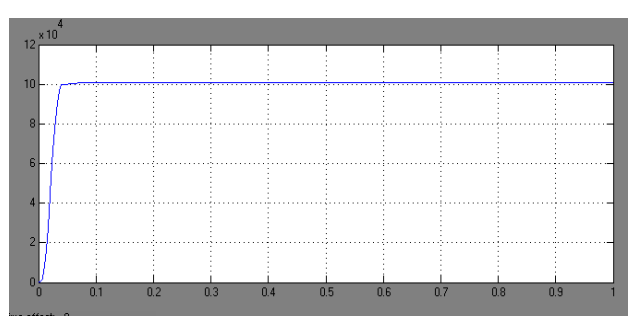

Fig.4d. Reactive power at 11 bus

TABLE I: REAL POWER, REACTIVE POWER AND VoltAGE OF DifFERENT BUSES WITH AND WITHOUT IPFC

\begin{tabular}{|c|l|l|l|c|c|c|}
\hline $\begin{array}{l}\text { Bus } \\
\text { no }\end{array}$ & $\begin{array}{l}\text { P(MW) } \\
\text { without } \\
\text { IPFC }\end{array}$ & $\begin{array}{l}\text { P(MW) } \\
\text { with } \\
\text { IPFC }\end{array}$ & $\begin{array}{l}\text { Q(MVAR) } \\
\text { without } \\
\text { IPFC }\end{array}$ & $\begin{array}{l}\text { Q(MVA } \\
\text { R) with } \\
\text { IPFC }\end{array}$ & $\begin{array}{l}\text { VOLTAGE } \\
\text { without } \\
\text { IPFC }\end{array}$ & $\begin{array}{l}\text { VOLTA } \\
\text { GE with } \\
\text { IPFC }\end{array}$ \\
\hline 5 & 0.212 & 0.208 & 0.099 & 0.098 & 7198 & 7144 \\
\hline 11 & 0.418 & 0.421 & 0.131 & 0.132 & 6783 & 6798 \\
\hline 12 & 0.35 & 0.36 & 1.482 & 1.51 & 6868 & 6931 \\
\hline 13 & 0.338 & 0.344 & 1.065 & 1.08 & 6069 & 6112 \\
\hline 19 & 0.341 & 0.346 & 0.134 & 0.136 & 6868 & 6931 \\
\hline 21 & 0.286 & 0.31 & 0.093 & 0.101 & 6295 & 6540 \\
\hline
\end{tabular}

TABLE II: INJECTED VOLTAGE AND REACTIVE POWER OF DIFFERENT BUSES

\begin{tabular}{|c|c|c|c|}
\hline $\begin{array}{c}\text { INJECTED } \\
\text { VOLTAGE } \\
\text { (KV) }\end{array}$ & $\begin{array}{c}\text { BUS 11 } \\
\text { Q(MVAR) }\end{array}$ & $\begin{array}{c}\text { BUS 19 } \\
\text { Q(MVAR) }\end{array}$ & $\begin{array}{c}\text { BUS 21 } \\
\text { Q(MVAR) }\end{array}$ \\
\hline 10 & 0.131 & 0.135 & 0.098 \\
\hline 12 & 0.132 & 0.136 & 0.101 \\
\hline 14 & 0.133 & 0.137 & 0.104 \\
\hline
\end{tabular}

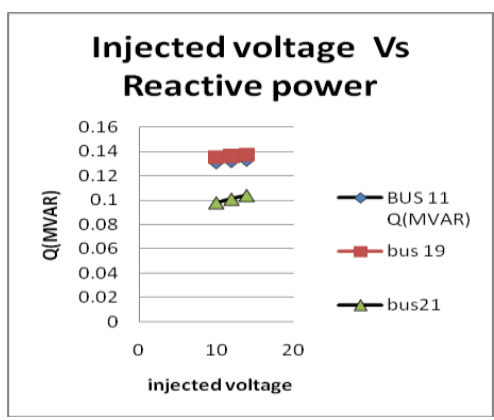

Fig.5.variation of reactive power

The injected voltage at different lines and change in real power of different buses are given in Table 3. Fig.5.shows that the real power increases with the increase in the injected voltage.

TABLE III: THE REAL POWER INCREASES WITH THE INCREASE IN THE INJECTED VOLTAGE

\begin{tabular}{|c|c|c|c|}
\hline INJECTED VOLTAGE (KV) & $\begin{array}{c}\text { BUS 11 } \\
\text { P(MW) }\end{array}$ & $\begin{array}{c}\text { BUS 19 } \\
\text { P(MW) }\end{array}$ & $\begin{array}{c}\text { BUS } \\
21 \\
\text { (MW) }\end{array}$ \\
\hline 10 & 0.42 & 0.345 & 0.301 \\
\hline 12 & 0.421 & 0.346 & 0.31 \\
\hline 14 & 0.422 & 0.348 & 0.317 \\
\hline
\end{tabular}

\section{CONCLUSION}

The 30 bus systems is modeled and simulated with and without IPFC using matlab simulink. The voltage profile is improved by adding IPFC.The IPFC pushes more power to 
the buses with higher load. The real power and the reactive power can be easily controlled with the help of IPFC.The simulation results are in line with the predicted results. The contribution of this work is the development of simulink model for 30 bus system. The scope of the present work is to model and simulate thirty bus system using matlab. The sixty four bus system is yet to be simulated.

\section{ACKNOWLEDGMENT}

The simulation studies are conducted in the power system simulation lab, Bharath University. The authors would like to thank HOD, EEE, Bharath University for providing the facilities.

\section{REFERENCES}

[1] L. Gyugyi, K. Sen. Kalyan, Colin D. Schauder: The interline power flow controller concept: a new approach to power flow management in transmission systems, IEEE Transactions on Power Delivery, Vol.14, No.3, pp.1115-1122.

[2] R. Strzelecki, H. Supronowicz: Power factor in AC supply systems and improvements methods, Publishing house of the Technical University of Warszawa, Warszawa 2000.

[3] R. Strzelecki, J. Kukluk, H. Supronowicz, H. Tunia: A universal symmetrical topologies for active power line conditioners, EPE'99Lausanne.

[4] R. Strzelecki, G. Benysek, J. Bojarski: Interline power flow controller, SENE Conference, POLAND, 2001, Vol. 2, pp. 591-596.

[5] H. Fujita, Y. Watanabe, H. Akagi: Control and analysis of a unified power flow controller, IEEE Trans. Power Electronics, 14, 6, 1999 , pp.1021-1027.

[6] R. Strzelecki, J. Bojarski, G. Benysek: Probabilistic method for parallel filter's power selection in interline power flow controller, EPE-PEMC'2002-Dubrivnik.

[7] F.Z.Peng,J.-Lai,J.McKeever,andJ.Van Coevering, "A multi level voltage-Source converter system with balanced DC voltages, "in Proc.IEEEPESC'95,1995,pp.1144-1150.
[8] Y.ChenandB.T.Ooi,“Multimodul a multi level rectifier/inverter link Within dependent reactive power control,"IEEE Trans.Power Delivery, vol.13,pp.902-908,July1998.

[9] D.E.Soto-Sanchez and T.C. Green, "Voltage balance and control in a multi-level unified power flow controller,"IEEE Trans.Power Delivery vol.16,pp.732-738,Oct.2001.

[10] P.Usha Rani and B. S.RamaReddy. Modeling and digital simulation of Interline Power Flow Controller System. International Journal of Computer and Electrical Engineering, Vol. 2, No. 3, June, 2010 1793-8163.

[11] Power Flow Analysis of a power system in the in presence of Interline Power Flow Controller (IPFC) V. Naresh Babu. Sivanagaraju Ch. Dmanabharajuand T. Ramana ARPN Journal of Engineering and Applied Sciences VOL. 5, NO. 10, OCTOBER 2010.

[12] By using Genetic Algorithm Method for optimal location of FACTS devices in the Deregulated Power. PRAKASH G.BURADE, DR.J.B.HELONDE. Journal of Theoretical and Applied Information Technology - 2010 JATIT

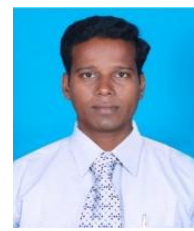

G. Irusapparajan, received his B.E. Degree from Manonmaniam Sundaranar University in 2000, M.E degree from Annamalai University in 2005, M.H.R.M.,from Annamalai University. He is currently a research scholar at Bharath University, Chennai. His area of research interest is Interline Power Flow Controllers (IPFC).

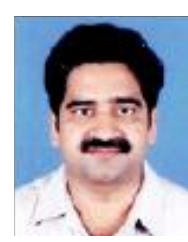

S. RamaReddy, received his M.E degree from College of Engineering, Anna University, Chennai, India in 1987. He received Ph.D degree in the area of Resonant Converters from College of Engineering, Anna University, Chennai India in 1995. Presently he is working as Professor in Electrical \& Electronics Dept., Jerusalem College of Engineering, Chennai. He has worked in Tata Consulting Engineers and Anna University, Chennai, India. He is fellow member of Institution of Electronics and Telecommunication Engineers (India), Life Member of Institution of Engineers (India), Member of ISTE, Member of CSI and Member of SPE, India. He has authored text books on Power Electronics, Electronic Circuits and Electromagnetic Fields. He has published 30 research papers in reputed journals. His research areas are Power Electronic Converters, Drives and FACTS 